\title{
A prática jurídica no CCJ/UFSC: breve histórico
}

\author{
Ildemar Egger ${ }^{1}$ \\ Universidade Federal de Santa Catarina \\ egger@ccj.ufsc.br
}

\section{Resumo}

O presente texto visa resguardar a memória de um dos importantes serviços prestados pela Universidade Federal de Santa Catarina - UFSC à comunidade, através do Escritório Modelo de Assistência Jurídica - EMAJ do Centro de Ciências Jurídicas - CCJ. Trata-se do atendimento jurídico oferecido gratuitamente às pessoas de origem popular, ditas hipossuficientes. O objetivo, como afirmamos inicialmente, visa a não se perderem dados históricos, mantendo-se a memória dos fatos que levaram a criação e desenvolvimento do Núcleo de Prática Jurídica - NPJ, cuja atuação dá-se através do EMAJ. A produção do texto resulta da vivência e experiência empírica no funcionamento da prática jurídica na UFSC. O período refere-se à instalação dos trabalhos de assistência jurídica exercida através da Faculdade de Direito (1961) até o momento em que se comemoram os 80 anos de sua fundação (2012).

Palavras-chave: Prática jurídica. Assistência jurídica. Atendimento jurídico a pessoas hipossuficientes.

\section{Legal practice in CCJ/UFSC: brief history}

\begin{abstract}
Abastract
This text aims to safeguard the memory of one of the important services provided by the Federal University of Santa Catarina-UFSC to community, through Legal Assistance model Office - Legal Sciences Center EMAJ-CCJ, the legal service offered for free people of popular origin, said hipossuficientes. The objective as stated initially aims to not lose historical data, keeping the memory of the facts that led to the creation and development of legal practice-NPJ whose performance is by the EMAJ. The production of the text is the result of experience and empirical experience of the functioning of the legal practice at UFSC. The period refers to the installation of legal assistance work carried out by the Faculty of law (1961) until the time that celebrates 80 years of its Foundation (2012).
\end{abstract}

Keywords: Legal Practice. Legal Assistance. Legal assistance to persons hipossuficientes.

\footnotetext{
1 Doutor em Direito pela UFSC, Professor Adjunto IV do Curso de Direito do CCJ/UFSC, tendo sido Coordenador do NPJ - Núcleo de Prática Jurídica (EMAJ) do CCJ/UFSC, de Nov/2001 a Mar/2005 e de Set/2006 a Dez/2007, atualmente é Coordenador de Extensão do CCJ/UFSC.
}

Esta obra está licenciada sob uma Licença Creative Commons. 


\section{INTRODUÇÃO}

No momento em que se comemoram os 80 anos da criação da Faculdade de Direito, atual Curso de Direito da Universidade Federal de Santa Catarina, não podemos deixar de traçar, ainda que de forma sucinta, a trajetória e importância do Escritório Modelo de Assistência Jurídica - EMAJ do Centro de Ciências Jurídicas - CCJ da Universidade Federal de Santa Catarina - UFSC, que foi criado em 1961 como DEAPRAJ ${ }^{1}$, sendo parte integrante do antigo Departamento de Direito Processual e Prática Forense - DPP.

É importante ressaltar que a iniciativa de exercitar a prática forense, mediante o atendimento da população hipossuficiente, foi do Centro Acadêmico XI de Fevereiro CAXIF, que, em face da lacuna então existente na antiga Faculdade de Direito, atual CCJ, resolveu exercer essa atividade, buscando dar acesso à justiça a essa população menos favorecida, fato este que resultou na criação do DEAPRAJ ${ }^{1}$ acima referido, cujo objetivo, desde então, é propiciar aos acadêmicos do Curso de Direito do CCJ/UFSC uma iniciação prática no exercício da advocacia durante sua formação acadêmica, visando qualificá-los como futuros profissionais da área jurídica, conciliando, desse modo, a função social por estes exercida, os interesses da população usuária dos serviços jurídicos prestados pelo EMAJ e o acesso à justiça.

\section{MATERIAL E MÉTODOS}

Em 1993, o EMAJ passou a contar com um espaço físico próprio, situado ao lado do estacionamento do CSE/CCJ como um anexo do CCJ, edificado com madeiras doadas pela ELETROSUL, encaminhadas como inservíveis.

Com essa reestruturação, o EMAJ passou a contar com dez gabinetes usados pelos acadêmicos de direito para atendimento da população economicamente menos favorecida,

\footnotetext{
${ }^{1}$ O DEAPRAJ, que estava previsto no Estatuto do Centro Acadêmico aprovado em 1960, foi criado por iniciativa do CAXIF, sob a presidência do então acadêmico de Direito, Napoleão Amarante, e foi instalado em 1961. A sigla original significava "Departamento de Entrosagem do Acadêmico na Prática Jurídica", sendo, portanto, um departamento do CAXIF. Posteriormente, passou a ser exercido no DPP. Nos primeiros anos, os professores da faculdade orientavam os alunos no DEAPRAJ. No Direito do Trabalho, o orientador era o Prof. Henrique Stodieck; no Direito Civil, os professores Osmundo Wanderley da Nóbrega e Alves Pedrosa; no Processo Penal, o Prof. Geraldo Gama Salles, que começou na faculdade apenas como orientador do DEAPRAJ, somente entrando como professor no início dos anos 1970; no Direito Penal, o Prof. Marcílio Medeiros; e na Medicina Legal, o Prof. Madeira Neves.
}

Esta obra está licenciada sob uma Licença Creative Commons. 
passando a contar cada um desses gabinetes com um computador (PC 486); uma sala de aula; uma sala dos professores para atendimento e orientação dos acadêmicos sempre que estes necessitavam; além da área destinada aos serviços de secretaria; e, na ausência de uma sala de espera, os clientes, depois de encaminhados pela secretaria do EMAJ, aguardavam ser atendidos em bancos situados no corredor, em frente aos gabinetes das respectivas equipes de alunos.

Nesse mesmo ano, através de convênio firmado em 09 de julho de 1993, entre a Universidade Federal de Santa Catarina - UFSC, o Tribunal de Justiça do Estado de Santa Catarina - TJ/SC, a Procuradoria Geral de Justiça - PGJ/SC e a Seccional Catarinense da Ordem dos Advogados do Brasil - OAB/SC, foi instalada a Vara de Exceção do Fórum da UFSC, para atender as demandas vinculadas ao EMAJ.

Em face do crescente número de demandas patrocinadas pelo EMAJ, nos termos de convênio havido com a UFSC, o TJ/SC edificou e, em 11 de fevereiro de 1999, inaugurou o Fórum Distrital do Norte da Ilha, denominado Fórum Desembargador José Arthur Boiteaux, localizado no campus universitário, em substituição à Vara de Exceção acima referida.

Em decorrência do projeto de extensão "Reestruturação Física e Didático-Pedagógica do EMAJ", bem como dos seminários intitulados "Repensar o EMAJ", que foram por nós coordenados, em julho de 2002, fez-se uma reestruturação no espaço físico, pedagógico e metodológico do EMAJ, modernizando-o e adequando-o às configurações de espaço físico que vem sendo utilizado nos grandes escritórios de advocacia; estruturando o espaço com quatro salas, uma para cada turma (A, B, C e D) de alunos do EMAJ, para que cada uma estivesse próxima de seu professor-orientador, sendo cada uma delas organizada em cinco Estações de Atendimento, onde os alunos, em duplas, passaram a realizar seus estudos, bem como o atendimento aos usuários dos serviços do EMAJ; separou-se a área administrativa da área acadêmica, buscando aprimorar o espaço de atividade dos servidores técnicoadministrativos, bem como visando melhorar o desempenho dos alunos e as atividades dos docentes, aproximando os professores de seus orientandos.

Assim, os alunos estagiários que eram distribuídos em dez equipes, média de quatro alunos por gabinete, passaram a compor cinco duplas por sala, total de vinte duplas no período matutino e vinte duplas no período vespertino, atuando em cada uma das referidas Estações de Atendimento, nas quais foi disponibilizado um computador por dupla de alunos.

Esta obra está licenciada sob uma Licença Creative Commons. 
Destacamos, também, que a reforma realizada em 2002 buscou oferecer respeito e dignidade aos usuários dos serviços prestados através do EMAJ, destinando-lhes uma sala de espera, como um espaço de exercício da cidadania.

Em meados de 2005, foi inaugurado o novo prédio do CCJ/UFSC, passando o EMAJ a ocupar a sua área térrea, aproximando-o do Fórum do Norte da Ilha.

\section{RESULTADOS E ANÁLISE}

Com referência aos projetos de extensão, é importante ressaltar o que prescreve o parágrafo $2^{\circ}$ do artigo 10 do Regulamento do EMAJ: “ $§ 2^{\circ}$. Os projetos alternativos de estágio funcionam sob a forma de atividades de extensão ou, conjuntamente, de extensão e pesquisa, e possuem necessariamente um professor responsável". De modo que, além das atividades desenvolvidas nas disciplinas de Prática Jurídica Real I, II, III e IV, incumbe a todo e qualquer professor do CCJ oferecer projetos de extensão que supram eventuais lacunas que entendam serem possíveis de ocorrer ou mesmo projetos que visem oferecer estudos, pesquisa e extensão em áreas do direito que entendam serem importantes para complementar a formação prática do acadêmico ou que, a seu ver, não são procuradas pelos usuários do EMAJ, até porque, apresentando os projetos de extensão que entendam serem completares à formação acadêmica, os professores do DIR não estarão sendo omissos em face das alternativas que, a seu ver, poderiam oferecer para o aprimoramento dos serviços prestados pelo EMAJ e para o melhor aproveitamento da classe discente.

Nesse sentido, cumpre destacar que, através do EMAJ, têm sido desenvolvidas atividades como, por exemplo, o projeto de extensão “Assessoria Jurídica Ambiental” e o projeto de extensão "Atendimento Jurídico Itinerante", que tem atuado nos programas sociais designados "Ação Social”, nos quais, em um determinado dia, são oferecidos diversos serviços à comunidade. De igual forma merecem destaque os trabalhos desenvolvidos na busca de implantação do Núcleo de Mediação e Arbitragem junto ao EMAJ/CCJ/UFSC. Nesse sentido, não é demais lembrarmos que as tratativas para tal implantação tiveram origem na preposição do saudoso Professor Doutor Luis Alberto Warat em conjunto com o professor relator deste texto, a qual teve parecer favorável da Coordenação do EMAJ e foi aprovada por unanimidade pelo Colegiado Delegado do Departamento de Direito - DIR. 
Entre seus objetivos, o Núcleo de Mediação visa privilegiar o ensino, a difusão e a prática da Mediação, além de buscar qualificar os futuros profissionais do Curso de Direito e áreas afins, durante sua formação acadêmica, para a utilização de métodos extrajudiciais de resolução de controvérsias, através, principalmente, do atendimento da população hipossuficiente que procura os serviços do EMAJ para solução de seus conflitos.

Assim, com a finalidade de estimular os alunos do Curso de Direito nos estudos e na prática da Mediação, em 2006 ministramos no CCJ um Curso de Extensão de Qualificação de Mediadores e Árbitros, em parceria com a Câmara Brasileira de Mediação e Arbitragem Empresarial - CBMA, com carga horária de 120 horas/aula. Durante o ano de 2009/2010, através do Projeto Pacificar oferecido pelo Programa Nacional de Segurança Pública com Cidadania - PRONASCI e pelo Ministério da Justiça - MJ, desenvolvemos várias palestras acerca do tema Mediação, no auditório do CCJ/UFSC, com o fulcro de promover a implantação da Mediação junto ao EMAJ. Além disso, é oferecida, na $6^{\text {a }}$ fase do Curso de Direito, a disciplina curricular "Negociação e Mediação".

Assim, o Núcleo de Mediação do CCJ/UFSC se propõe a, através da aplicação desse método extrajudicial, não só agilizar a resolução do conflito, como também humanizar o tratamento das partes controversas, assegurando-lhes a dignidade, o respeito humano, bem como o exercício da cidadania.

No início do semestre letivo de 2011, além da divulgação dos métodos extrajudiciais de resolução de conflitos junto aos alunos, professores e clientela do EMAJ, propôs-se à Coordenação do EMAJ que os casos atendidos fossem encaminhados, inicialmente, para o Núcleo de Mediação para a tratativa de uma solução amigável, através dos métodos extrajudiciais de resolução de controvérsias, buscando humanizar o trato dos conflitos, bem como uma solução menos traumatizante que a judicial, na qual as decisões são impostas às partes; enquanto, nos métodos extrajudiciais, a solução é encontrada pelas próprias partes.

Entretanto, cumpre observar que, apesar da importância que se tem destacado para a solução dos conflitos com a utilização dos métodos extrajudiciais (negociação, conciliação, Mediação, arbitragem etc.), a comunidade do CCJ não tem desenvolvido tal atividade como deveria, com maior participação e interesse; deixando, assim, de acompanhar a tendência mundial do uso desse método mais humano na solução dos conflitos, até porque esse interesse tem sido fortemente demonstrado pelo Poder Judiciário, pelo Conselho Nacional de Justiça - 
CNJ, pela Ordem dos Advogados do Brasil, bem como por diversos órgãos públicos e conselhos profissionais, inclusive pela iniciativa privada, como, por exemplo, a Confederação das Associações Comerciais Brasileiras - CACB (vide, p.ex.: www.cbmae.org.br ); de modo que, é plenamente justificada a necessidade da continuidade desse trabalho de implantação do Núcleo de Mediação do CCJ, tema este que já foi objeto de preocupação do Ministério da Justiça - MJ, com o Projeto Pacificar, desenvolvido por este professor, como coordenador do mesmo, em 2009/2010.

Observamos que o Núcleo de Mediação oferece atendimento à comunidade de origem popular, principalmente em questões relativas a direitos patrimoniais disponíveis, ao Direito Civil, em especial na área da família e litígios decorrentes.

Os critérios de atendimento são os fixados pelo EMAJ, ou seja, ser pessoa carente (critério socioeconômico verificado através de triagem), e, em caso de discussão patrimonial, os bens devem ser de pequeno valor. Após a triagem, os casos devem ser encaminhados ao Núcleo de Mediação para tentativa de solução amigável/consensual. Caso não se obtenha sucesso, a questão deve ser remetida para o EMAJ para as providências legais, e, se for o caso, promover o acesso à justiça.

Observamos ainda que a equipe técnica do EMAJ é formada por professores, técnicoadministrativos, alunos monitores, alunos bolsistas de extensão, de treinamento, de estágio e uma média de 340 alunos da graduação que, a partir da $7^{\mathrm{a}}$ fase, cumprem, durante quatro semestres, o estágio curricular do Curso de Direito da UFSC.

Com os dados obtidos desde a informatização em novembro de 1991, constatamos, através de levantamentos estatísticos realizados, que, a cada semestre, um percentual de aproximadamente $70 \%$ dos usuários dos serviços do EMAJ concentra-se na busca de procedimentos envolvendo o direito de família, $10 \%$ no direito das obrigações, $5 \%$ no direito das coisas, $5 \%$ no direito das sucessões, $1 \%$ na lei de registros públicos, $3 \%$ no direito penal, $2 \%$ no direito trabalhista, $2 \%$ no direito previdenciário e $2 \%$ distribuídos em outras áreas. 


\section{CONSIDERAÇÕES FINAIS}

Como anotação final, cumpre ainda destacar que a importância da prestação de serviços jurídicos à comunidade hipossuficiente pela UFSC, através do EMAJ, tem sido reconhecida por inúmeras instituições congêneres, não só do nosso Estado, como de diversos outros Estados da Federação, que nos têm procurado como modelo para a constituição de seus respectivos Núcleos de Prática Jurídica.

Em suma, com este breve histórico, procuramos trazer uma noção, ainda que propedêutica, da importância do EMAJ, não só para a formação dos futuros profisssionais da área jurídica, como para o acesso da comunidade hipossuficiente à justiça, sendo a atuação do EMAJ e de seus congêneres equiparada, por inúmeras jurisprudências, tanto pelos Tribunais de Justiça dos Estados como pelo Superior Tribunal de Justiça, à Defensoria Pública, inclusive, no que concerne à contagem em dobro dos prazos processuais (ver, p.ex.: REsp $\mathrm{N}^{\mathrm{o}}$ 1.106.213-SP, relatora Min. Nancy Andrighi), dando conta da importância das atividades desenvolvidas pelos Escritórios Modelos e de seu reconhecimento pelo próprio Poder Judiciário. 